\title{
Effect of diet on asthma and allergic sensitisation in the International Study on Allergies and Asthma in Childhood (ISAAC) Phase Two
}

\author{
Gabriele Nagel, ${ }^{1}$ Gudrun Weinmayr, ${ }^{1}$ Andrea Kleiner, ${ }^{1}$ Luis Garcia-Marcos, ${ }^{2}$ \\ David P Strachan, ${ }^{3}$ the ISAAC Phase Two Study Group
}

- Supplementary materials are published online only. To view these files please visit the journal online (http://thorax.bmj. com).

${ }^{1}$ Institute of Epidemiology, Ulm University, Germany

${ }^{2}$ Pediatric Respiratory and Allergy Units, "Arrixaca"

University Children's Hospital, University of Murcia and CIBER of Epidemiology and Public Health (CIBERSP), Murcia, Spain ${ }^{3}$ Division of Community Health Sciences, St George's Hospital, University of London, London, UK

\section{Correspondence to}

Dr Gabriele Nagel, Institute of Epidemiology, Ulm University, Helmholtzstr. 22, Ulm 89081, Germany;

gabriele.nagel@uni-ulm.de

For author footnote see end of the article.

Received 29 September 2009 Accepted 6 April 2010

\section{ABSTRACT}

Background The increasing prevalence of asthma and allergy might be related to diet, particularly in Western countries. A study was undertaken to assess the association between dietary factors, asthma and allergy in a large international study including objective measurements of atopy.

Methods Between 1995 and 2005, cross-sectional studies were performed in 29 centres in 20 countries. Parental questionnaires were used to collect information on allergic diseases and exposure factors and data from 50004 randomly selected schoolchildren (8-12 years, 29579 with skin prick testing) were analysed. Random effect models for meta-analysis were applied to calculate combined ORs.

Results Fruit intake was associated with a low prevalence of current wheeze in affluent $\left(0 \mathrm{R}_{\mathrm{adj}} 0.86\right.$, $95 \% \mathrm{Cl} 0.73$ to 1.02$)$ and non-affluent countries $\left(\mathrm{OR}_{\mathrm{adj}}\right.$ $0.71,95 \% \mathrm{Cl} 0.57$ to 0.88 ). Consumption of fish in affluent countries $\left(O \mathrm{R}_{\text {adj }} 0.85,95 \% \mathrm{Cl} 0.74\right.$ to 0.97$)$ and of cooked green vegetables in non-affluent countries $\left(\mathrm{OR}_{\mathrm{adj}} 0.78,95 \% \mathrm{Cl} 0.65\right.$ to 0.95$)$ was associated with a lower prevalence of current wheeze. Overall, more frequent consumption of fruit, vegetables and fish was associated with a lower lifetime prevalence of asthma, whereas high burger consumption was associated with higher lifetime asthma prevalence. None of the food items was associated with allergic sensitisation. Except for fruit juice and fruit consumption, no associations were found with atopic wheeze. Food selection according to the 'Mediterranean diet' was associated with a lower prevalence of current wheeze and asthma ever $\left(p_{\text {trend }}=0.03\right)$.

Conclusion Diet is associated with wheeze and asthma but not with allergic sensitisation in children. These results provide further evidence that adherence to the 'Mediterranean diet' may provide some protection against wheeze and asthma in childhood.

\section{INTRODUCTION}

Changes in the prevalence of asthma and allergy may be related to dietary factors that are typical of a Western lifestyle. ${ }^{12}$ In the International Study on Allergies and Asthma in Childhood (ISAAC) Phase One, ecological inverse relationships were observed between starch, cereal and vegetable consumption and asthma in children. ${ }^{3}$

Special attention was given to dietary fat intake after a study of children in former Eastern Germany linked consumption of high margarine (positively) and butter (negatively) with hay fever. ${ }^{4}$ An involvement of dietary fat intake in the pathophysiology of atopic diseases would be plausible because the composition of the ingested fatty acids is known to modulate immune reactions. ${ }^{5}$ There is also some evidence that fish rich in n-3-poly unsaturated fatty acids (PUFA) has anti-inflammatory properties and may modulate the immune response towards a Th1 type. ${ }^{1}$

Decreased consumption of fresh fruit and vegetables, which are rich in antioxidants, has been reported to have a role in the development of allergic diseases. ${ }^{1367}$ There is also some evidence that dietary antioxidants such as vitamins $\mathrm{E}$ and $\mathrm{C}$ and $\beta$-carotene are inversely associated with asthma in adults. ${ }^{8}$

Recent research has also focused on components of the typical 'Western' diet such as burgers and fizzy drinks, which were found to contribute to allergic sensitisation. ${ }^{1}{ }^{2}$ Increasing fast food consumption has been suggested as a factor underlying the rising prevalence of asthma. ${ }^{9}$

Dietary patterns such as the 'Mediterranean diet', which is characterised by high fruit and vegetable intake and low consumption of saturated fatty acids (SFA) from animal source and found to be associated with better survival in adults, ${ }^{10}$ have been associated with a lower prevalence of asthma symptoms among children in Spain, ${ }^{11}{ }^{12}$ Crete $^{13}$ and Mexico. ${ }^{14}$

The purpose of the present study was to investigate associations of different foods and of the "Mediterranean diet' with asthma symptoms and diagnosis, atopic sensitisation and bronchial hyper-responsiveness (BHR) among children in a large international study. The inclusion of objective measurements overcomes some limitations of previous reports.

\section{METHODS}

The rationale and methods of the ISAAC Phase Two have already been described in full elsewhere. ${ }^{15}$ In brief, random samples of at least 10 schools in a defined geographical area were chosen and children ( $n \geq 1000$ per centre) were invited to participate. Overall, about 63000 schoolchildren $76.4 \%$ of those eligible) took part. Parental questionnaires, identical to those used in ISAAC Phase One, ${ }^{16}$ were used to collect data on symptoms of asthma, rhinitis and eczema between 1995 and 2005. For the present analyses, 50004 children aged 8-12 years from 29 centres in 20 countries with a complete set of parental responses on dietary variables were included.

Most centres invited all children for skin prick testing (SPT), while blood samples were collected mostly in subsamples of children stratified 
according to wheezing status during the past year (approximately 100 wheezers and 100 non-wheezers per centre). The stratified subsampling was applied by most centres for lung function measurements and BHR testing. Approval of the local ethics committees was obtained by all centres. ${ }^{15} 17$

\section{Exposure assessment}

Based on the hypotheses that low intake of antioxidants and PUFA and high intake of SFA and Western foods are associated with a high prevalence of asthma and allergy, the following food items were selected: meat, fish, fresh fruit, raw green vegetables, cooked green vegetables, burgers, fruit juice and fizzy drinks (for detailed questions and prevalence see online supplement).

The following potential confounders were considered: sex; age (years); current exposure to environmental tobacco smoke (ETS) ('Does anybody at present smoke inside your child's home?' Yes/ No); number of siblings (0, 1-2, $\geq 3)$; parental atopic disease ('Has the child's mother or father ever had any of the following diseases: asthma, hay fever or eczema?' Yes/No); and exercise ( $\geq 4$ times a week vs $<4$ times a week).

A score of the 'Mediterranean diet' pattern was derived according to the consumption frequency of food items. Points were assigned for 'low' consumption (less than once per week; score 0), 'regular' consumption (more than once a week; score 1) and 'frequent' consumption (at least once per day; score 2). Vegetables (raw green and cooked), fruit, fruit juice and fish were considered as 'pro-Mediterranean' foods and meat, burgers and fizzy drinks were considered as 'anti-Mediterranean' foods. Scores for the 'anti- Mediterranean' foods were reversed (ie, $2=$ low consumption, $0=$ frequent consumption). The points for each of the eight items were added up to a summary score.

We classified the study centres into two broad categories on the basis of gross national income (GNI) per capita using the World BankAtlas method ${ }^{18}$ in order to assess the difference in the strength of any association between diet and wheezing with 'affluent' and 'non-affluent' countries (GNI $<\$ 9200$ per year per capita).

\section{Outcome}

The question 'Has your child had wheezing or whistling in the chest in the past 12 months?' was used as the indicator for childhood asthma. In addition, the lifetime prevalence of asthma was investigated using the question 'Has your child ever had asthma?'. SPTs were performed on 29579 children using six common aeroallergens: Dermatophagoides pteronyssinus, $D$ farinae, cat hair, Alternaria tenuis, mixed tree and grass pollen (ALK, Hørsholm, Denmark). In addition, data of locally relevant allergens tested in 15 centres were included. At least one positive reaction (weal size $\geq 3 \mathrm{~mm}$ after subtraction of the negative control) was defined as a positive SPT. Atopic wheeze was defined as wheeze during the past year and a positive SPT. ${ }^{19}$

Spirometry and test of BHR were performed according to American Thoracic Society (ATS) criteria ${ }^{20}$ and are described in detail elsewhere ${ }^{1517}$ (see online supplement).

\section{Statistical analysis}

Partial correlation coefficients were calculated in order to show the relationship between foods which are known to be correlated. For analysis involving stratified subsamples (mainly BHR and IgE analysis), weighted prevalences and risk estimates were calculated. ${ }^{21}$ Random effect models for meta-analysis were applied to calculate crude $(\mathrm{OR})$ and adjusted $\mathrm{ORs}\left(\mathrm{OR}_{\mathrm{adj}}\right)$ with $95 \%$ CIs combined for affluent and non-affluent countries ${ }^{22}$ as well as for all centres combined. In multivariate models the potential confounders included were: sex, age, current exposure to ETS, number of siblings, exercise and maternal atopic disease to control for both increased risk of atopy and potential lifestyle modifications. In addition, models with maternal education as an indicator for socioeconomic position were investigated. Further stratification by maternal atopic disease, sex, atopic and non-atopic wheeze was performed. Tests for linear trend were calculated based on the estimates for each dietary category (scored $0,1,2)$ in a linear regression model and the significance was tested by the Wald test ( $\left.p_{\text {trend }}\right)$. By calculation of Cochrane $\mathrm{O}$ and $\mathrm{I}^{2}$, no substantial heterogeneity between centres was detected (data not shown). ${ }^{23}$ Differences between strata were assessed by the z-test. Depending on prevalence and completeness of the variables, the numbers of subjects and sometimes the number of centres in the models differ.

SAS release 9.1 (SAS Institute) was used to analyse the data.

\section{RESULTS}

Correlations between dietary factors are summarised in table 1 for affluent centres (lower triangle) and non-affluent countries (upper triangle). Most food items were only weakly correlated $(\rho<0.3)$. Somewhat stronger positive correlations were apparent between the consumption of fruit, raw and cooked green vegetables in both affluent and non-affluent countries. Furthermore, the intake of fizzy drinks, meat, burgers and fruit juice was correlated in non-affluent countries. However, none of the partial correlations were greater than $\rho=0.5$.

The 'Mediterranean score' correlated well $(\rho>0.5)$ with consumption of fruit, raw and cooked green vegetables in affluent countries and raw and cooked green vegetables in non-affluent countries.

Table 2 shows crude and adjusted ORs for wheeze during the past year by food items and affluence. In the multivariate models (model 2) the consumption of fresh fruit was significantly $(p<0.05)$ associated with less wheeze during the past year in non-affluent countries $\left(\mathrm{OR}_{\mathrm{adj}} 0.71,95 \% \mathrm{CI} 0.57\right.$ to 0.88 ; $\left.\mathrm{Q}=5.2 ; \mathrm{I}^{2}=0.0 \%\right)$ and non-significantly in affluent countries $\left(\mathrm{OR}_{\text {adj }} 0.86,95 \% \mathrm{CI} 0.73\right.$ to $\left.1.02 ; \mathrm{Q}=5.8 ; \mathrm{I}^{2}=0.0 \%\right)$. The intake of fruit juice was significantly related to lower prevalence of wheeze in non-affluent countries only $\left(\mathrm{OR}_{\text {adj }} 0.80,95 \% \mathrm{CI} 0.68\right.$ to $0.94, \mathrm{Q}=7.0 ; \mathrm{I}^{2}=0.0 \%$ ). High consumption of cooked green vegetables was significantly associated with fewer wheezers in non-affluent countries only $\left(\mathrm{OR}_{\mathrm{adj}} 0.78,95 \% \mathrm{CI} 0.65\right.$ to 0.95 ; $\left.\mathrm{Q}=4.5 ; \mathrm{I}^{2}=0.0 \%\right)$. There was a similar trend for raw green vegetables $\left(\mathrm{OR}_{\mathrm{adj}} 0.86,95 \% \mathrm{CI} 0.72\right.$ to $\left.1.02, \mathrm{Q}=7.9 ; \mathrm{I}^{2}=0.0 \%\right)$. In affluent countries, children with high fish intake experienced wheeze less often during the previous year than children in the comparison group $\left(\mathrm{OR}_{\mathrm{adj}} 0.85,95 \%\right.$ CI 0.74 to $0.97, \mathrm{Q}=7.4$; $\mathrm{I}^{2}=0.0 \%$ ), whereas in non-affluent countries this association was in the same direction but not statistically significant $\left(O R_{\text {adj }} 0.91\right.$, $95 \%$ CI 0.75 to $\left.1.10, Q=10.3 ; I^{2}=22.6 \%\right)$. Meat consumption was not associated with wheeze during the previous year in either group of centres. In non-affluent countries, however, an inverse relationship was found between burger consumption and wheeze $\left(\mathrm{OR}_{\text {adj }} 0.76,95 \%\right.$ CI 0.61 to $\left.0.95, \mathrm{Q}=3.5 ; \mathrm{I}^{2}=0.0 \%\right)$, contrasting with a positive but non-significant association in affluent countries (OR 1.11, 95\% CI 0.96 to $1.26 ; \mathrm{Q}=4.0$; $\mathrm{I}^{2}=0.0 \%$ ). These two ORs for burger consumption differ significantly $(p<0.005$ for interaction). A similar but less significant pattern emerged for fizzy drinks.

Further adjustment for maternal education as an indicator of socioeconomic position did not substantially change the direction or the strength of the associations.

Concerning different intake frequencies, no major differences due to affluence and adjustment for maternal education emerged, 
Table 1 Correlation $(\rho)$ between food items adjusted for centre (partial correlation) by affluence status (non-affluent upper triangle, affluent lower triangle)*

\begin{tabular}{|l|l|l|l|l|l|l|l|l|l|}
\hline & Meat & Fish & $\begin{array}{l}\text { Fresh } \\
\text { fruit }\end{array}$ & $\begin{array}{l}\text { Raw green } \\
\text { vegetables }\end{array}$ & $\begin{array}{l}\text { Cooked green } \\
\text { vegetables }\end{array}$ & Burger & Fruit Juice & $\begin{array}{l}\text { Fizzy } \\
\text { drinks }\end{array}$ & $\begin{array}{l}\text { Mediterranean } \\
\text { Score }\end{array}$ \\
\hline Meat & & 0.24 & 0.22 & 0.14 & $-0.005 \mathrm{NS}$ & 0.31 & 0.32 & 0.32 & $\mathbf{- 0 . 2 3}$ \\
\hline Fish & 0.08 & & 0.17 & 0.14 & 0.14 & 0.16 & 0.17 & 0.11 & $\mathbf{0 . 2 6}$ \\
\hline Fresh fruit & 0.16 & 0.13 & & 0.30 & 0.15 & 0.13 & 0.41 & 0.24 & $\mathbf{0 . 4 6}$ \\
\hline $\begin{array}{l}\text { Raw green } \\
\text { vegetables }\end{array}$ & 0.06 & 0.17 & 0.38 & & 0.43 & 0.13 & 0.23 & 0.06 & $\mathbf{0 . 5 8}$ \\
\hline $\begin{array}{l}\text { Cooked green } \\
\text { vegetables }\end{array}$ & 0.22 & 0.16 & 0.32 & 0.38 & & 0.004 & 0.03 & -0.09 & $\mathbf{0 . 5 8}$ \\
\hline Burger & 0.08 & $0.01 \mathrm{NS}$ & -0.05 & -0.04 & -0.02 & & 0.34 & 0.35 & $\mathbf{- 0 . 2 1}$ \\
\hline Fruit juice & 0.04 & 0.05 & 0.14 & 0.09 & 0.04 & 0.04 & & 0.45 & $\mathbf{0 . 2 6}$ \\
\hline Fizzy drinks & $-0.01 \mathrm{NS}$ & $-0.001 \mathrm{NS}$ & -0.10 & -0.06 & -0.14 & 0.18 & 0.10 & & $\mathbf{- 0 . 2 7}$ \\
\hline $\begin{array}{l}\text { Mediterranean } \\
\text { Score }\end{array}$ & $\mathbf{0 . 0 1 N S}$ & $\mathbf{0 . 3 6}$ & $\mathbf{0 . 6 0}$ & $\mathbf{0 . 6 1}$ & $\mathbf{0 . 5 6}$ & $\mathbf{- 0 . 2 7}$ & $\mathbf{0 . 3 9}$ & $\mathbf{- 0 . 3 6}$ & \\
\hline
\end{tabular}

${ }^{*}$ All $p$ values were $<0.001$ apart from the correlations marked 'NS' ( $\left.p>0.05\right)$.

so further models were calculated combining all centres without adjustment for maternal education. Table 3 shows the ORs for current wheeze in the previous year, asthma ever, skin prick positivity and BHR. Compared with none or occasional consumption, the consumption of burgers $\geq 3$ times per week was associated with a higher lifetime asthma prevalence $\left(\mathrm{OR}_{\text {adj }} 1.42\right.$, $95 \%$ CI 1.08 to $\left.1.87, Q=18.8 ; I^{2}=20.0 \%\right)$. A high frequency of fish intake ( $p_{\text {trend }}=0.04$ ) as well as raw vegetables ( $\geq 3$ times vs never/ occasionally: $\mathrm{OR}_{\text {adj }} 0.86,95 \% \mathrm{CI} 0.74$ to $0.98, \mathrm{Q}=19.9 ; \mathrm{I}^{2}=14.4 \%$ ) and cooked green vegetables $\left(\mathrm{OR}_{\mathrm{adj}} 0.86,95 \%\right.$ CI 0.74 to 0.997 , $\mathrm{Q}=16.9 ; \mathrm{I}^{2}=5.2 \%$ ) was related to lower asthma prevalence. Frequencies of meat, fruit juice and fizzy drink consumption were not related to asthma ever. SPT positivity (table 3) and elevated specific IgE concentrations (data not shown) were not related to the selected dietary factors. BHR (table 3) as an indicator of asthma was not associated with any of the selected foods.

Analyses performed after stratification by SPT positivity are shown in table 4. In affluent countries, none of the food items was associated with wheeze among children with a positive SPT. In contrast, in non-affluent countries regular consumption of fish, raw vegetables, fruit juice and burgers were statistically significantly associated with fewer wheezers among children with a positive SPT, but not among children with a negative SPT. Among children with a negative SPT, regular fruit intake was associated with fewer wheezers in affluent and non-affluent countries. In affluent countries, regular meat intake was also inversely related to wheeze during the past year among atopic and non-atopic children.

A higher score indicating adherence to a 'Mediterranean' dietary pattern was associated with a lower prevalence of wheezing (OR 0.97 per unit increase of score, $95 \%$ CI 0.94 to 0.99 , $p_{\text {trend }}=0.03$, $\mathrm{Q}=14.9 ; \mathrm{I}^{2}=5.8 \%$ ) and asthma (OR 0.95 per unit, 95\% CI 0.92 to $\left.0.99, \mathrm{p}_{\text {trend }}=0.03, \mathrm{Q}=17.7, \mathrm{I}^{2}=26.6 \%\right)$. However, no statistically significant association was observed between the 'Mediterranean diet' score and SPT positivity (OR 1.00 per score unit, 95\% CI 0.95 to $1.04 ; \mathrm{Q}=29.4 ; \mathrm{I}^{2}=52.4 \%$ ) and BHR (OR 1.05 per score unit, $95 \%$ CI 0.96 to $\left.1.14 ; \mathrm{Q}=14.2 ; \mathrm{I}^{2}=22.4 \%\right)$.

\section{DISCUSSION}

This large multicentre international study including both affluent and non-affluent countries provides further evidence for protective associations of regular fish, fruit and vegetable consumption with symptoms of asthma. In contrast to non-affluent countries, frequent burger consumption was related to a higher prevalence of wheeze and asthma in non-atopic children in affluent centres. No significant associations were found for meat and fizzy drink intake. In addition, none of the objective markers studied (SPT positivity, elevated specific IgE levels and saline-induced BHR) were related to any of the selected food items. In non-affluent countries, however, a protective effect of consumption of burgers, fish, raw vegetables and fruit juice against wheeze was stronger among children with a positive SPT.

\section{Strengths and limitations}

Several possible limitations of the study need to be considered. Data on habitual diet were collected retrospectively by parental questioning which may have introduced recall bias. However, in these young children, parents provide reliable information on current diet. $^{24}$ In addition, only a few selected items of common foods were considered based on the hypotheses that plant food is inversely associated with asthma and a 'Western' diet is positively associated with asthma. Furthermore, based on the ISAAC questionnaire, we could not adjust for total energy intake and body mass index. However, most other studies in children did not adjust for total energy intake. Multiple comparisons were performed which needs to be considered for interpretation of the results. Among the strengths are the use of the standardised ISAAC questionnaires and methodology in all centres and the inclusion of non-affluent countries. Furthermore, we were able to adjust for parental atopy, which may have introduced some bias related to food selection in allergic subjects. However, due to the cross-sectional study design, reverse causation cannot be completely excluded.

\section{Fruit and vegetables}

Our findings of inverse associations between asthma and frequency of fruit and vegetable consumption are in line with previous studies in children. ${ }^{325}$ Fruit and vegetables contain antioxidants and other biologically active factors which may contribute to the favourable effect of fruit consumption in asthma. $^{6}$ In particular, foods rich in vitamin $\mathrm{C}$ have been reported to relate to better lung function and fewer asthma symptoms. ${ }^{6} 6$ In clinical studies, dietary vitamin $\mathrm{E}$ intake has been shown to be inversely associated with plasma IgE levels, an effect which is likely to be mediated by different mechanism(s). ${ }^{2}$ Furthermore, it has been reported that carotenoids and vitamins $\mathrm{C}$ and $\mathrm{E}$ positively influence pulmonary function. ${ }^{27}$

Consistent with our findings in the ISAAC Phase One ecological study, centres with a high average intake of vegetables found a lower prevalence of wheeze among children aged 13-14 years. ${ }^{3}$ Further evidence of inverse associations for fruit 


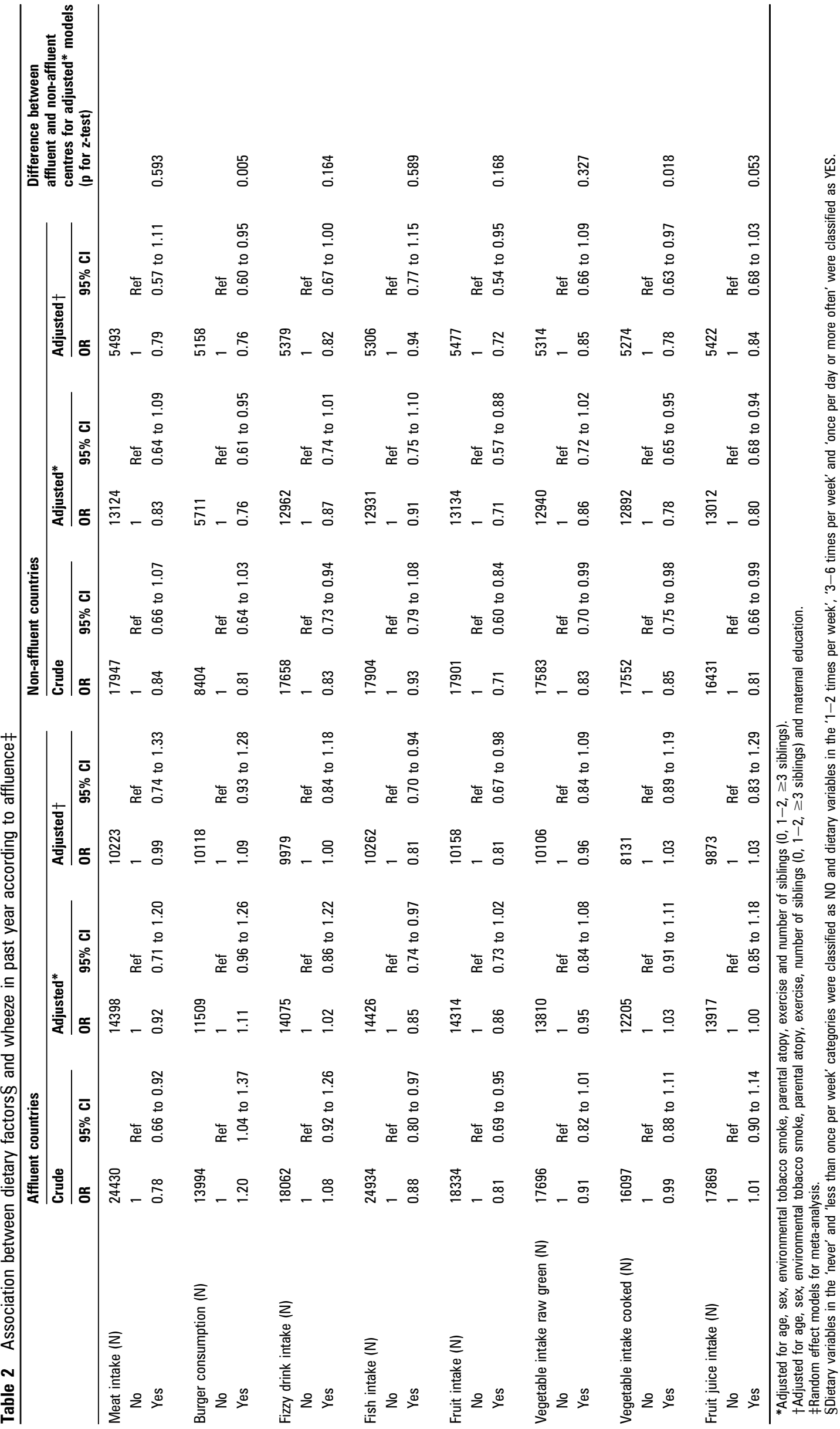


Table 3 Association between the consumption of selected foods and wheeze in the past year, asthma ever, skin prick test for atopy and specific lgE

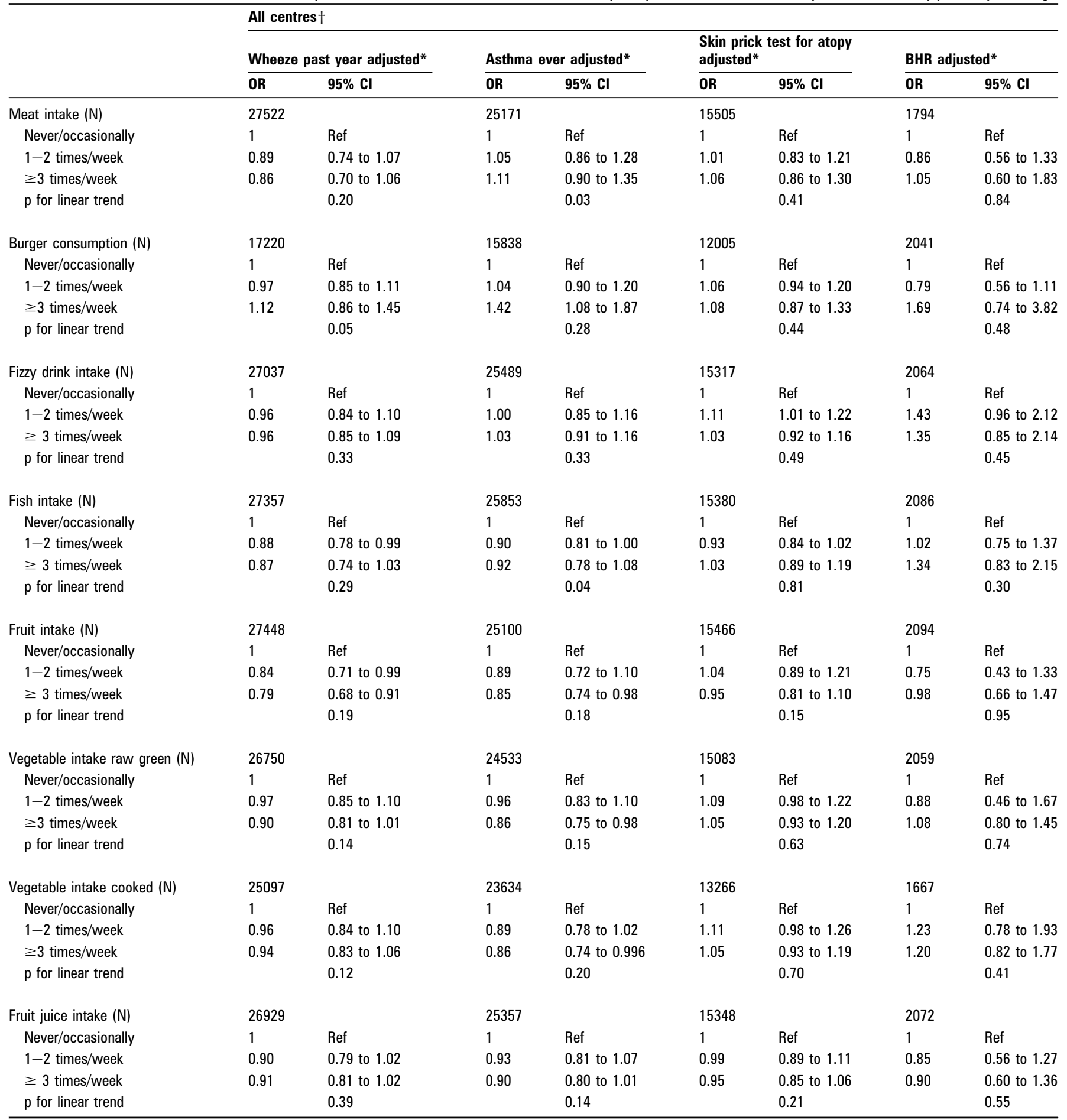

*Adjusted for age, sex, environmental tobacco smoke, parental atopy, exercise and number of siblings $(0,1-2, \geq 3$ siblings).

tRandom effect models for meta-analysis.

BHR, bronchial hyper-responsiveness.

and vegetable consumption comes from other studies either focused on intake frequency 72528 or on biomarkers of exposure. $^{29}$ In contrast, a lack of association between vegetable intake and asthma has been reported among Dutch children. ${ }^{30}$ One possible explanation for an inverse association between the consumption of cooked green vegetables and wheeze in nonaffluent countries could be the differential selection of vegetables and the preparation method as well as possible differences in the wheeze phenotype.
We found no inverse associations between fruit and vegetable consumption and BHR or lung function, but protective associations have been reported. ${ }^{263132} \mathrm{~A}$ high intake of apples and pears was associated with less BHR in a cross-sectional study among young adults in Australia. ${ }^{31}$ Low intakes of fruit juices have been associated with significantly reduced lung function in subjects aged 11-19 years. ${ }^{26}$ In a study in men from Italy, Finland and The Netherlands, high fruit and vegetable consumption was positively associated with pulmonary function. ${ }^{32}$ 
Table 4 Association between dietary factors $\ddagger$ and wheeze in past year according to skin prick test (SPT) and national gross national income (GNI) per capita†

\begin{tabular}{|c|c|c|c|c|c|c|c|c|c|c|}
\hline & \multicolumn{5}{|c|}{ Affluent countries } & \multicolumn{5}{|c|}{ Non-affluent countries } \\
\hline & \multicolumn{2}{|c|}{$\begin{array}{l}\text { Wheeze among } \\
\text { SPT positive* }\end{array}$} & \multicolumn{2}{|c|}{$\begin{array}{l}\text { Wheeze among SPT } \\
\text { negative* }\end{array}$} & \multirow{2}{*}{$\begin{array}{l}\text { Difference } \\
\text { between strata } \\
\text { (p for z-test) }\end{array}$} & \multicolumn{2}{|c|}{$\begin{array}{l}\text { Wheeze among SPT } \\
\text { positive* }\end{array}$} & \multicolumn{2}{|c|}{$\begin{array}{l}\text { Wheeze among SPT } \\
\text { negative* }\end{array}$} & \multirow{2}{*}{$\begin{array}{l}\text { Difference } \\
\text { between strata } \\
\text { (p for z-test) }\end{array}$} \\
\hline & $\overline{\mathbf{O R}}$ & $95 \% \mathrm{Cl}$ & OR & $95 \% \mathrm{Cl}$ & & $\overline{\mathbf{O R}}$ & $95 \% \mathrm{CI}$ & $\overline{\mathbf{O R}}$ & $95 \% \mathrm{Cl}$ & \\
\hline Meat intake (N) & 2095 & & 3420 & & & 1176 & & 4380 & & \\
\hline No & 1 & Ref & 1 & Ref & & 1 & Ref & 1 & Ref & \\
\hline Yes & 0.85 & 0.46 to 1.58 & 0.57 & 0.34 to 0.95 & 0.323 & 0.71 & 0.41 to 1.22 & 1.12 & 0.67 to 1.85 & 0.229 \\
\hline Burger consumption (N) & 1880 & & 5894 & & & 519 & & 3459 & & \\
\hline No & 1 & Ref & 1 & Ref & & 1 & Ref & 1 & Ref & \\
\hline Yes & 0.94 & 0.72 to 1.23 & 1.29 & 0.99 to 1.68 & 0.097 & 0.33 & 0.16 to 0.66 & 0.93 & 0.69 to 1.26 & 0.008 \\
\hline Fizzy drink intake (N) & 2560 & & 6559 & & & 1202 & & 4996 & & \\
\hline No & 1 & Ref & 1 & Ref & & 1 & Ref & 1 & Ref & \\
\hline Yes & 0.92 & 0.74 to 1.14 & 1.11 & 0.98 to 1.38 & 0.222 & 0.68 & 0.45 to 1.04 & 0.90 & 0.69 to 1.17 & 0.288 \\
\hline Fish intake (N) & 2608 & & 6619 & & & 1172 & & 4957 & & \\
\hline No & 1 & Ref & 1 & Ref & & 1 & Ref & 1 & Ref & \\
\hline Yes & 1.02 & 0.76 to 1.35 & 0.78 & 0.62 to 0.98 & 0.153 & 0.51 & 0.32 to 0.81 & 1.20 & 0.94 to 1.54 & 0.001 \\
\hline Fruit intake (N) & 2589 & & 6566 & & & 1152 & & 4866 & & \\
\hline No & 1 & Ref & 1 & Ref & & 1 & Ref & 1 & Ref & \\
\hline Yes & 0.88 & 0.63 to 1.21 & 0.72 & 0.53 to 0.97 & 0.374 & 0.47 & 0.21 to 1.02 & 0.61 & 0.45 to 0.85 & 0.529 \\
\hline Vegetable intake raw green (N) & 2493 & & 6436 & & & 1170 & & 4063 & & \\
\hline No & 1 & Ref & 1 & Ref & & 1 & Ref & 1 & Ref & \\
\hline Yes & 0.98 & 0.77 to 1.24 & 0.87 & 0.69 to 1.10 & 0.515 & 0.46 & 0.28 to 0.78 & 0.88 & 0.67 to 1.14 & 0.026 \\
\hline Vegetable intake cooked green (N) & 2135 & & 4992 & & & 1078 & & 4038 & & \\
\hline No & 1 & Ref & 1 & Ref & & 1 & Ref & 1 & Ref & \\
\hline Yes & 1.07 & 0.76 to 1.48 & 0.98 & 0.72 to 1.33 & 0.709 & 0.59 & 0.35 to 0.98 & 0.78 & 0.58 to 1.04 & 0.354 \\
\hline Fruit juice intake (N) & 2563 & & 6534 & & & 1193 & & 5034 & & \\
\hline No & 1 & Ref & 1 & Ref & & 1 & Ref & 1 & Ref & \\
\hline Yes & 0.92 & 0.71 to 1.19 & 1.40 & 0.97 to 2.04 & 0.065 & 0.47 & 0.32 to 0.69 & 0.87 & 0.66 to 1.14 & 0.011 \\
\hline
\end{tabular}

*Adjusted for age, sex, environmental tobacco smoke, parental atopy, exercise and number of siblings $(0,1-2, \geq 3$ siblings $)$.

†Random effect models for meta-analysis.

‡Dietary variables in the 'never' and 'less than once per week' categories were classified as NO and dietary variables in the '1-2 times per week', '3-6 times per week' and 'once per day or more often' were classified as YES.

\section{Fish consumption}

Fish is rich in n-3 PUFAs which have been shown to counterbalance pro-allergic $\mathrm{T}$ helper (Th)2 activity. $^{33}$ Our results of a protective association of fish consumption with asthma are in line with the Dutch ISAAC Phase Two subsample using a more detailed semiquantitative food frequency questionnaire and objective indicators such as SPT and BHR, ${ }^{30}$ a study among children aged 6.5 years in Spain ${ }^{7}$ and another one carried out in 10-14-year-old schoolchildren in Sweden. ${ }^{34}$ Our observations of no association between fish intake, BHR and SPT are consistent with the results of a prospective study on $n-3$ and n- 6 fatty acids, asthma and atopy among children aged 5 years ${ }^{35}$ and a study using fatty acids in serum cholesterol esters as biomarkers of exposure. $^{36}$

\section{Meat and burger consumption}

In line with previous research, we found the consumption of burgers to be related to a higher asthma prevalence. ${ }^{9}{ }^{12}$ Fast food is rich in industrially hydrogenated vegetable fats such as margarine and meat from ruminant animals which are dietary sources of trans-fatty acids. There is some evidence that dietary intake of trans-fatty acids is associated with asthma and atopy. ${ }^{37}$ However, meat consumption in general was not asso- ciated with any of the outcomes in our study, in line with other reports. 912 The frequency of burger consumption could be considered as a proxy for unknown lifestyle factors which may vary depending on the societal context, environmental and other lifestyle factors. It is therefore of interest that the association with burgers differed significantly between affluent and nonaffluent countries in our analysis, in particular by SPT status in non-affluent countries.

\section{'Mediterranean diet' score}

In line with other reports, we observed an inverse relationship between adherence to a 'Mediterranean' dietary pattern and both current wheeze ${ }^{11} 13$ and asthma ever. ${ }^{12}{ }^{14}$ The 'Mediterranean diet' is characterised by high intake of antioxidants and n-3-PUFA and low intake of SFA and trans-fatty acids, which have been shown to be contribute to a lower asthma prevalence. ${ }^{1}$

\section{CONCLUSION}

In summary, our observations support previous reports that the adherence to a 'Mediterranean diet' may provide protection against wheeze and asthma in childhood. As consumption of fish, fruit and vegetables is widely recommended for prevention of cardiovascular disease and cancer, our findings suggest that 
these public health initiatives are unlikely to be harmful in relation to childhood asthma symptoms and may be beneficial in reducing the prevalence of wheezing among children in diverse settings around the world. However, the causal significance of this observation has to be confirmed in prospective studies and experimental trials.

The ISAAC Phase Two Study group consists of: The ISAAC Phase Two Coordinating and Data Centre: S K Weiland† (Director), G Büchele, C Dentler, A Kleiner, P Rzehak, G Weinmayr (Institute of Epidemiology, Ulm University, Ulm, Germany).Principal investigators: A Priftanji, A Shkurti, J Simenati, E Grabocka, K Shyti, S Agolli, A Gurakuqi (Tirana, Albania); R T Stein, M Urrutia de Pereira, M H Jones, P M Pitrez (Uruguaiana, Brazil); P J Cooper, M Chico (Pichincha Province, Ecuador); Y Z Chen (Beijing, China); N S Zhong (Guangzhou, China); C K W Lai (National Coordinator), G W K Wong (Hong Kong, China); M-A Riikjärv, T Annus (Tallinn, Estonia); I Annesi-Maesano (Créteil, France); M Gotua, M Rukhadze, T Abramidze, I Kvachadze, L Karsanidze, M Kiladze, N Dolidze (Tbilisi, Georgia); W Leupold, U Keil, E von Mutius, S K Weiland† (Dresden, Germany); E von Mutius, U Keil, S K Weiland† (Munich, Germany); P Arthurt, E Addo-Yobo (Kintampo, Ghana); C Gratziou (National Coordinator), K Priftis, A Papadopoulou, C Katsardis (Athens, Greece); J Tsanakas, E Hatziagorou, F Kirvassilis (Thessaloniki, Greece); M Clausen (Reykjavik, Iceland); J R Shah, R S Mathur, R P Khubchandani, S Mantri (Mumbai, India); F Forastiere, R Di Domenicantonio, M De Sario, S Sammarro, R Pistelli, M G Serra, G Corbo, C A Perucci (Rome, Italy); V Svabe, D Sebre, G Casno, I Novikova, L Bagrade (Riga, Latvia); B Brunekreef, D Schram, G Doekes, P H N Jansen-van Vliet, N A H Janssen, F J H Aarts, $\mathrm{G}$ de Meer (Utrecht, The Netherlands); J Crane, K Wickens, D Barry (Hawkes Bay, New Zealand); W Nystad, R Bolle, E Lund (Tromsø, Norway); J Batlles Garrido, T Rubi Ruiz, A Bonillo Perales, Y Gonzalez Jiménez, J Aguirre Rodriguez, J Momblan de Cabo, A Losilla Maldonado, M Daza Torres (Almeria, Spain); L García-Marcos (National Coordinator), A Martinez Torres, J J Guillén Pérez, A Piñana López, S Castejon Robles (Cartagena, Spain); G García Hernandez, A Martinez Gimeno, A L Moro Rodríguez, C Luna Paredes, I Gonzalez Gil (Madrid, Spain); M M Morales Suarez-Varela, A Llopis González, A Escribano Montaner, M Tallon Guerola (Valencia, Spain); L Bråbäck (National Coordinator), M Kjellman, L Nilsson, X-M Mai (Linköping, Sweden); L Bråbäck, A Sandin (Östersund, Sweden); Y Saraçlar, S Kuyucu, A Tuncer, C Saçkesen, V Sumbulŏglu, P Geyik, C Kocabas, (Ankara, Turkey); D P Strachan, B Kaur (West Sussex, UK); N El-Sharif, B Nemery, F Barghuthy, S Abu Huij, M Qlebo (Ramallah, West Bank).ISAAC Steering Committee: N Ait-Khaled (Paris, France); H R Anderson and D P Strachan* (London, UK); C Flohr* and H Williams (Nottingham, UK); F

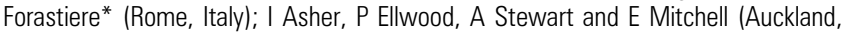
New Zealand); J Crane, N Pearce and R Beasley (Wellington, New Zealand); B Björkstén (Stockholm, Sweden); B Brunekreef* (Utrecht, The Netherlands); S Foliaki (Nuku'alofa, Kingdom of Tonga); L García-Marcos (Murcia, Spain); U Keil (Münster, Germany), E von Mutius* (Munich, Germany): S K Weiland* ${ }^{*}$, G Weinmayr* (Ulm, Germany); C K W Lai and G W K Wong (Hong Kong, China); J Mallol (Santiago, Chile); S Montefort (Naxxar, Malta); J Odhiambo (Nairobi, Kenya); C Robertson (Parkville, Australia). ${ }^{*}$ Also members of the ISAAC Phase Two Steering Group. †Deceased.

Acknowledgements The authors thank all children, parents, teachers, field workers and laboratory workers for their enormous contributions to this collaborative study. ALK generously provided reagents for field work in several low income countries without charge.

Funding The coordination and central laboratory analyses of the European centres were funded by the Fifth Framework Programme of the European Commission (QLK4-CT-1999-01288). The agencies funding the field work are listed elsewhere. ${ }^{15}$

Competing interests None.

Ethics approval This study was conducted with local ethical committee approval.

Provenance and peer review Not commissioned; externally peer reviewed.

\section{REFERENCES}

1. Devereux G, Seaton A. Diet as a risk factor for atopy and asthma. J Allergy Clin Immunol 2005;115:1109-17.

2. Fogarty A, Britton J. The role of diet in the aetiology of asthma. Clin Exp Allergy 2000;30:615-27.

3. Ellwood P, Asher MI, Bjorksten B, et al. Diet and asthma, allergic rhinoconjunctivitis and atopic eczema symptom prevalence: an ecological analysis of the International Study of Asthma and Allergies in Childhood (ISAAC) data. ISAAC Phase One Study Group. Eur Respir J 2001:17:436-43.

4. von Mutius E, Weiland SK, Fritzsch C, et al. Increasing prevalence of hay fever and atopy among children in Leipzig, East Germany. Lancet 1998;351:862-6.
5. Kankaanpaa P, Sutas Y, Salminen S, et al. Dietary fatty acids and allergy. Ann Med 1999;31:282-7.

6. Forastiere $\mathbf{F}$, Pistelli $R$, Sestini $P$, et al. Consumption of fresh fruit rich in vitamin $C$ and wheezing symptoms in children. SIDRIA Collaborative Group, Italy (Italian Studies on Respiratory Disorders in Children and the Environment). Thorax 2000;55:283-8.

7. Chatzi L, Torrent M, Romieu I, et al. Diet, wheeze, and atopy in school children in Menorca, Spain. Pediatr Allergy Immunol 2007;18:480-5.

8. Nagel G, Linseisen J. Dietary intake of fatty acids, antioxidants and selected food groups and asthma in adults. Eur J Clin Nutr 2005;59:8-15.

9. Wickens K, Barry D, Friezema A, et al. Fast foods-are they a risk factor for asthma? Allergy 2005:60:1537-41.

10. Trichopoulou A, Orfanos P, Norat T, et al. Modified Mediterranean diet and survival: EPIC-elderly prospective cohort study. BMJ 2005;330:991

11. Castro-Rodriguez JA, Garcia-Marcos L, Alfonseda Rojas JD, et al. Mediterranean diet as a protective factor for wheezing in preschool children. J Pediatr 2008;152:823-8.

12. Garcia-Marcos L, Canflanca IM, Garrido JB, et al. Relationship of asthma and rhinoconjunctivitis with obesity, exercise and Mediterranean diet in Spanish schoolchildren. Thorax 2007;62:503-8.

13. Chatzi L, Apostolaki G, Bibakis I, et al. Protective effect of fruits, vegetables and the Mediterranean diet on asthma and allergies among children in Crete. Thorax 2007;62:677-83

14. de Batlle J, Garcia-Aymerich J, Barraza-Villarreal A, et al. Mediterranean diet is associated with reduced asthma and rhinitis in Mexican children. Allergy 2008:63:1310-16.

15. Weiland SK, Bjorksten B, Brunekreef B, et al. Phase II of the International Study of Asthma and Allergies in Childhood (ISAAC II): rationale and methods. Eur Respir $J$ 2004:24:406-12.

16. Asher MI, Keil U, Anderson HR, et al. International Study of Asthma and Allergies in Childhood (ISAAC): rationale and methods. Eur Respir J 1995;8:483-91.

17. Buchele G, Rzehak P, Weinmayr G, et al. Assessing bronchial responsiveness to hypertonic saline using the stepwise protocol of Phase Two of the International Study of Asthma and Allergies in Childhood (ISAAC II) 2. Pediatr Pulmonol 2007:42:131-40.

18. World Bank. http://www.worldbank, 2005.

19. Weinmayr G, Weiland SK, Bjorksten B, et al. Atopic sensitization and the international variation of asthma symptom prevalence in children. Am J Respir Crit Care Med 2007;176:565-74.

20. Miller MR, Hankinson J, Brusasco V, et al. Standardisation of spirometry. Eur Respir J 2005;26:319-38

21. Richardson DB, Rzehak P, Klenk J, et al. Analyses of case-control data for additional outcomes. Epidemiology 2007;18:441-5.

22. Normand SL. Meta-analysis: formulating, evaluating, combining, and reporting. Stat Med 1999:18:321-59.

23. Higgins JP, Thompson SG, Deeks JJ, et al. Measuring inconsistency in metaanalyses. BMJ 2003;327:557-60.

24. Byers T, Trieber F, Gunter E, et al. The accuracy of parental reports of their children's intake of fruits and vegetables: validation of a food frequency questionnaire with serum levels of carotenoids and vitamins C, A, and E. Epidemiology 1993;4:350-5

25. Farchi S, Forastiere F, Agabiti N, et al. Dietary factors associated with wheezing and allergic rhinitis in children. Eur Respir J 2003;22:772-80.

26. Gilliland FD, Berhane $\mathrm{KT}$, Li YF, et al. Children's lung function and antioxidant vitamin, fruit, juice, and vegetable intake. Am J Epidemiol 2003;158:576-84.

27. Schunemann HJ, Grant BJ, Freudenheim JL, et al. The relation of serum levels of antioxidant vitamins $\mathrm{C}$ and $\mathrm{E}$, retinol and carotenoids with pulmonary function in the general population. Am J Respir Crit Care Med 2001;163:1246-55.

28. Hijazi N, Abalkhail B, Seaton A. Diet and childhood asthma in a society in transition: a study in urban and rural Saudi Arabia. Thorax 2000:55:775-9.

29. Harik-Khan RI, Muller DC, Wise RA. Serum vitamin levels and the risk of asthma in children. Am J Epidemiol 2004;159:351-7.

30. Tabak C, Wijga AH, de Meer G, et al. Diet and asthma in Dutch school children (ISAAC-2). Thorax 2006;61:1048-53.

31. Woods RK, Walters EH, Raven JM, et al. Food and nutrient intakes and asthma risk in young adults. Am J Clin Nutr 2003:78:414-21.

32. Tabak C, Smit HA, Rasanen L, et al. Dietary factors and pulmonary function: a cross sectional study in middle aged men from three European countries. Thorax 1999:54:1021-6

33. Black PN, Sharpe S. Dietary fat and asthma: is there a connection? Eur Respir J 1997:10:6-12

34. Nja F, Nystad W, Lodrup Carlsen KC, et al. Effects of early intake of fruit or vegetables in relation to later asthma and allergic sensitization in school-age children. Acta Paediatr 2005;94:147-54.

35. Almqvist C, Garden F, Xuan W, et al. Omega-3 and omega-6 fatty acid exposure from early life does not affect atopy and asthma at age 5 years. J Allergy Clin Immunol 2007:119:1438-44.

36. Bolte G, Kompauer I, Fobker M, et al. Fatty acids in serum cholesteryl esters in relation to asthma and lung function in children. Clin Exp Allergy 2006;36:293-302.

37. Weiland SK, von Mutius E, Husing A, et al. Intake of trans fatty acids and prevalence of childhood asthma and allergies in Europe. ISAAC Steering Committee. Lancet 1999:353:2040-1. 